\title{
Pathogenesis of hepatic septal fibrosis associated with Capillaria hepatica infection of rats
}

\author{
Patogenia da fibrose septal hepática associada com a infecção \\ por Capillaria hepatica em ratos
}

Antônio Benigno dos Santos ${ }^{1}$, Miguel Tolentino Junior ${ }^{1}$ and Zilton A. Andrade ${ }^{2}$

\begin{abstract}
Septal fibrosis is a common form of hepatic fibrosis, but its etiology and pathogenesis are poorly understood. Rats infected with the helminth Capillaria hepatica constitute a good experimental model of such fibrosis. To investigate the pathogenetic contribution of the several parasitic factors involved, the following procedures were performed in rats: a) regarding the role of eggs, these were isolated and injected either into the peritoneal cavity or directly into the liver parenchyma; b) for worms alone, 15-day-old infection was treated with mebendazole, killing the parasites before oviposition started; c) for both eggs and worms, rats at the $30^{\text {th }}$ day of infection were treated with either mebendazole or ivermectin. Eggs only originated focal fibrosis from cicatricial granulomas, but no septal fibrosis. Worms alone induced a mild degree of perifocal septal fibrosis. Systematized septal fibrosis of the liver, similar to that observed in the infected controls, occurred only in the rats treated with mebendazole or ivermectin, with dead worms and immature eggs in their livers. Thus, future search for fibrogenic factors associated with $\mathrm{C}$. hepatica infection in rats should consider lesions with both eggs and worms.
\end{abstract}

Key-words: Capillaria hepatica. Septal fibrosis. Pathogenesis. Liver.

Resumo A fibrose septal é uma forma comum de fibrose hepática, mas a sua etiologia e patogenia são ainda desconhecidas. Os ratos infectados com o verme Capillaria hepatica representam um bom modelo experimental para tal fibrose. Para verificar a contribuição de cada fator parasitário na patogenia, os seguintes experimentos foram realizados em ratos: a) para testar o papel dos ovos, estes foram isolados e injetados seja na cavidade peritoneal ou no interior do parênquima hepático; b) para verificar o papel dos vermes, foram tratados com mebendazol, ratos infectados aos 15 dias da inoculação; c) para o papel de ovos e vermes conjuntamente, os ratos com infecção de 30 dias foram tratados com mebendazol ou ivermectina. Os ovos injetados no fígado causaram fibrose focal, mas não fibrose septal; os vermes mortos antes da oviposição deram lugar apenas a discreta fibrose septal perifocal. Somente os animais tratados no $30^{\circ}$ dia da infecção, com ovos e vermes em desintegração, mostraram fibrose septal sistematizada, tal como a vista nos controles da infecção. Assim, as pesquisas visando isolar o(s) fator(es) fibrogênico(s) devem considerar particularmente as lesões focais induzidas por vermes em desintegração e ovos imaturos.

Palavras-chaves: Capillaria hepatica. Fibrose septal. Patogenia. Fígado.

Septal fibrosis of the liver is characterized by formation of long and thin fibrous septa along the acinar zone III, connecting central veins between them and, later on, to portal spaces, forming bridges. It is a peculiar type of hepatic fibrosis, that usually occurs as a mild and nonspecific change in most examples of chronic liver diseases of man, but that may assume prominence and diagnostic significance in cases of incomplete septal cirrhosis ${ }^{210}$ and chronic septal hepatitis ${ }^{7}$. Etiology and pathogenesis are poorly understood, especially in reference to cases of human pathology. Experimentally, the demonstration that septal fibrosis of the liver can be produced in rats by repeated intraperitoneal injections of pig serum ${ }^{19}$, has stimulated a great deal of research into this type of fibrosis. Bunchet et $\mathrm{al}^{3}$ have observed that the pathogenesis of septal fibrosis has an immunologic basis, by demonstrating that rats injected with pig serum during the neonatal period became tolerant and failed to develop septal fibrosis when repeatedly injected with pig serum in adult life.

In 1993, Ferreira and Andrade ${ }^{5}$ observed that rats infected with the helminth Capillaria hepatica regularly developed septal fibrosis of the liver, exhibiting a picture similar to that obtained with repeated pig-serum administration.

1. Estagiários acadêmicos, 2. Laboratório de Patologia Experimental do Centro de Pesquisa Gonçalo Moniz da Fundação Oswaldo Cruz, Salvador, BA, Brasil.

Address to: Dr. Zilton A. Andrade. R. Valdemar Falcão 121, 40295-001 Salvador, BA, Brazil.

Tel: 55 71-356-4320, r: 206. Fax: 55 71-356-2155.

e-mail:zilton@cpqgm.fiocruz.br

Recebido para publicação em 8/2/2000. 
The life cycle of $C$. hepatica in the rat is auto-limited, all the worms dying inside the liver, 30 to 40 days after infection. Disintegration of worms and liberation of their eggs within the liver provokes focal necroticinflammatory lesions, that soon undergo fibrous encapsulation. When all worms are dead and disintegrating and the focal encapsulated lesions are undergoing resorption, septal fibrosis starts its progressive course, eventually evolving toward cirrhosis.

The mechanism leading to septal fibrosis in this model is probably related to the slow release of stimulatory factors from dead worms and immature eggs sequestered within the focal encapsulated lesions.
These factors or molecules would ultimately stimulate Ito's fat-storing perisinusoidal cells to synthesize excess extracellular matrix, along the acinar zone III of the liver ${ }^{6}$. Besides such speculation, little has been investigated about the pathogenesis of septal fibrosis in C. hepaticainfected rats. Present investigation is a preliminary contribution to this subject. It will attempt to answer a very simple question regarding which of the parasitic factors - dead worms, their eggs or a combination of both - play the main role in the pathogenesis of septal fibrosis. It is hoped after this preliminary step that the strategies for further research on the molecular definition of the fibrogenic factors involved, may be facilitated.

\section{MATERIAL AND METHODS}

Animals. Adult outbred Wistar rats of both sexes, weighing 150 to $200 \mathrm{~g}$, maintained on a commercial balanced diet for rats and water ad libitum, were used.

Capillaria hepatica. Immature eggs were obtained from the liver of experimentally infected rats. The livers containing the eggs were homogenized in a blender at $1,000 \mathrm{rpm}$ during 3 minutes. The material was suspended in tap water and washed through sedimentation and decantation, until the supernatant fluid became clear. The sediment containing the eggs was placed in Petri dishes, maintained humidified with a solution of $0.5 \%$ formalin, at room temperature (25$28^{\circ} \mathrm{C}$ ), during $38-30$ days, to embryonate. The eggs were counted by means of a special glass chamber which held $1 \mathrm{ml}$ of the purified egg suspension.

Tissue for histology. Fragments of the liver were obtained by surgical biopsies and after necropsy. Both procedures were always performed with the animals under ether anesthesia and upon sterile conditions. Biopsy consisted of partial hepatectomy, made by means of a ligature placed and tightened around the middle of an exposed hepatic lobe. Pieces of the liver were immediately fixed in buffered $10 \%$ formalin and/or Bouin's fluid, embedded in paraffin and the $5 \mathrm{~mm}$-thicksections obtained were stained with hematoxylin and eosin and the picrosirius-red method for collagen.

Experiments. A total of four experiments were performed. Two of them were designed to investigate the role of immature eggs in inducing septal fibrosis of the liver; one referred to the role of dead worms alone, and another investigated the participation of both dead worms and eggs. A total of five groups were considered, consisting of one for each experiment, plus a control of the infection.

$1^{\text {st }}$ Group. Five rats were injected into the peritoneal cavity with 1,000 immature eggs, five times, with an interval of 15 days between the injections. Fifty days after the first injection a surgical biopsy of the liver was performed in each animal. All the animals were sacrificed 70 days after the first injection. The nodules formed

Immature eggs of $C$. hepatica injected into the peritoneal cavity caused local chronic granulomatous within the peritoneum and mesentery, in consequence of the injections of eggs, were removed and submitted to the same procedures as for the liver tissue.

$2^{\text {nd }}$ Group. Ten rats underwent abdominal surgery to expose the liver. In five of them a needle was introduced into the liver tissue from the capsule and then slowly removed while a total of $0.3 \mathrm{ml}$ of a suspension containing 1,000 to 3,000 immature eggs was being continuously injected. The remaining five animals received injections of approximately 3,000 immature eggs directly into a main mesenteric vein. No mortality occurred. All the animals were sacrificed 45 days after the procedures described.

$3^{\text {rd }}$ Group. Ten rats were infected with 800 embryonated eggs of $C$. hepatica administered by gavage. After 15 days, when only young worms without eggs were present in the liver, the animals were treated with the antihelminthic Mebendazole (Belfar, Belo Horizinte, MG, Brazil) administered by gastric tube during 5 successive days, in the daily dose of $5 \mathrm{mg} / \mathrm{kgbw}$. Two surgical liver biopsies were performed, respectively 30 and 60 days after treatment. One month after the last biopsy, 90 days after treatment, all the animals were sacrificed.

$4^{\text {th }}$ Group. Animals infected with 800 embryonated $C$. hepatica eggs were treated 30 days after inoculation, when worms and eggs were already present in the liver. Five animals were treated with Mebendazole, as previously described. The remaining five were treated with Ivermectin (Ivotan, Hoechst Roussel Vet. SA), administered orally in a single dose of $0.2 \mathrm{ml}$ of a solution containing $1 \%$ of the drug. Thirty and 60 days after treatment, the animals were submitted to surgical liver biopsies. Sacrifice of all animals occurred 90 days after treatment.

$5^{\text {th }}$ Group. Five rats were infected with 800 embryonated eggs. They were treated with saline $(0.5 \mathrm{ml})$ administered orally during five days after the $30^{\text {th }}$ day of infection. Except for the type of treatment, they were submitted to all the other procedures as for the two previous groups.

\section{ESULTS}

inflammation and fibrosis, involving the mesenteric fatty tissue. The eggs showed several degrees of 
disintegration, some were seen inside giant cells, others were calcified, and many appeared focally accumulated, forming discrete inflammatory nodules. The liver was not involved and appeared histologically to be within normal limits.

Eggs injected inside the liver appeared clustered or isolated in histological sections, always surrounded by a small area of dense focal fibrosis (Figures $1 \mathrm{~A}$ and $\mathrm{B}$ ). No traces of septal fibrosis appeared anywhere in the liver.

Treatment against $C$. hepatica with Mebendazole performed on the $15^{\text {th }}$ day of infection provoked the death of all the worms, before the egg-laying phase. Dead worms appeared necrotic, in various stages of disintegration, at the center of a lesion delimited by thick fibrous capsule and chronic inflammatory tissue. Small tracts of septal fibrosis were observed, radiating from the focal parasitic lesion. Fibrosis formed a criss-crossed pattern and extended from the periphery of the lesion to some distance inside the liver parenchyma (Figure 1D).
The majority of the liver tissue, situated away from the dead-worm lesions, presented free of fibrosis.

Animals treated with either Mebendazole or Ivermectin on the $30^{\text {th }}$ day of infection presented dead worms and eggs at the center of encapsulated necrotic-inflammatory lesions. Septal fibrosis was observed as a diffuse change throughout the liver, 40 days or longer after treatment. It formed fine threads of fibrous tissue making bridges between central veins, with extensions to portal spaces (Figure $1 \mathrm{E}$ and F). No differences were observed between the animals treated with Mebendazole or Ivermectin, as far as the focal parasitic lesions or the disposition and intensity of septal fibrosis were concerned.

Animals from the control group presented worms with early signs of disintegration in their livers during the $15^{\text {th }}$ day of infection (Figure $1 \mathrm{C}$ ) and after the $30^{\text {th }}$ day a complete picture of septal fibrosis, with focal lesions containing dead worms and eggs.
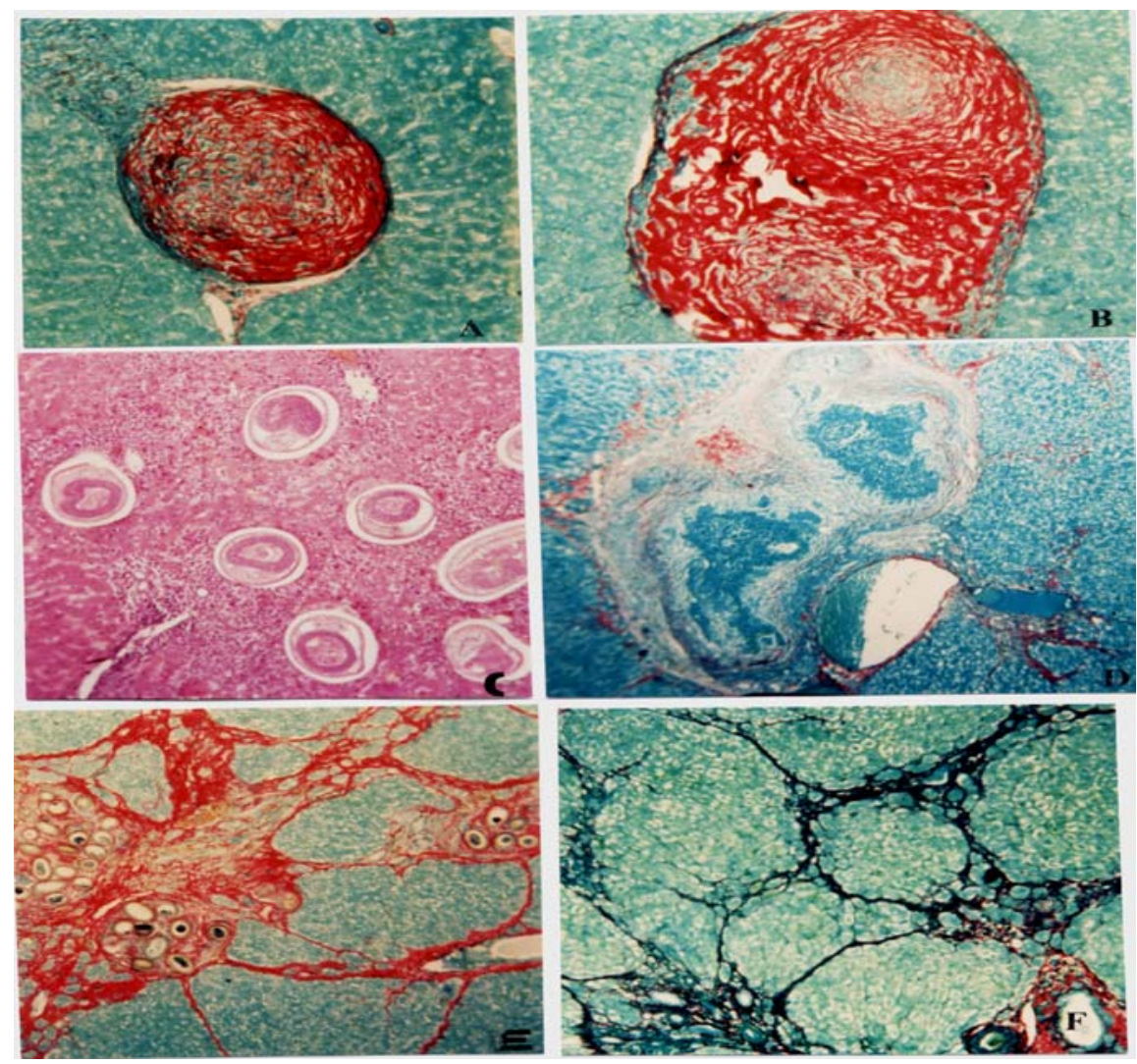

Figure 1 ( $A$ and $B$ ) - Focal fibrosis caused by the injection of immature $\mathrm{C}$. hepatica eggs into the liver. There is dense concentric deposition of collagen, but no traces of septal fibrosis. Picrosirius-red method for collagen, $A=160 X ; B=200 X$. Figure 1 (C) - Presence of young adult $C$. hepatica in early disintegration, surrounded by inflammation and necrosis of the liver tissue. Control, 15-day-old infection. Hematoxylin \& eosin, 160X. Fiqure 1 (D) - Fibrous encapsulation of central necrotic areas (old dead-worm lesions) with perifocal septal fibrosis. Fifteen-day-old infection, treated with mebendazole 40 days previously. Picrosirius-red method for collagen, 160X. Figure $1(E$ and $F$ ) - Full blown septal fibrosis of the liver seen in rats, 70 days after treatment with ivermectin $(E)$ and mebendazole $(F)$ of a 30-day-old $\mathrm{C}$. hepatica infection. Picrosirius-red method for collagen, 160X. 


\section{DISCUSSION}

According to the present data, neither $C$. hepatica eggs nor worms alone, appeared to be decisive factors for the induction of septal hepatic fibrosis in rats, as summarized in Table 1. Actually, a small degree of septal fibrosis formed around dead worm lesions in the liver of animals treated with mebendazole before oviposition. Although limited and focal, such changes suggest that dead and dying worms do play a role in the pathogenesis

Table 1 - Summary of the findings in the five experimental groups used to investigate the relative importance of eggs, worms and worms and eggs, in the pathogenesis of hepatic septal fibrosis in rats infected with Capillaria hepatica.

\begin{tabular}{lll}
\hline Groups & \multicolumn{1}{c}{ Description } & Septal fibrosis of the liver \\
\hline $1^{\text {st }}$ & intraperitoneal injections of immature eggs & absent \\
$2^{\text {nd }}$ & intrahepatic injections of immature eggs & absent \\
$3^{\text {rd }}$ & death of young adult worms before oviposition & mild, partial, perifocal \\
$4^{\text {th }}$ & death of adult worms after oviposition & marked \\
$5^{\text {th }}$ & control - infection with worms and eggs & marked \\
\hline
\end{tabular}

of septal fibrosis. However, the full picture of widespread hepatic septal fibrosis was only seen in animals presenting eggs and dead worms in their livers, either after drug treatment or not. As could be expected, curative treatment did not interfere with the further development of septal fibrosis, since in natural conditions the fibrosis usually starts after the death of worms ${ }^{6}$.

As previously reported, mebendazole and ivermectin exhibited strong curative effects against C. hepatica ${ }^{4}$. No live worms were seen in histological sections after treatment with any one of these drugs. Compared to the situation in control sections, the effect of the drug upon the immature eggs was not clear. It has been claimed that ivermectin destroys both worms and eggs ${ }^{5}$. As a matter of fact, this reference motivated the use of ivermectin in the present investigation. It seemed interesting to observe the evolution of the changes from 30 days of infection onward, after the elimination of eggs. However, neither the eggs appeared to be affected by treatment, nor the lesions seemed different from those of the other groups.

Immature $C$. hepatica eggs are biologically active. During natural infection they are retained within the liver for prolonged periods of time, but once in the external environment, with appropriate conditions of moisture and temperature, they are able to mature and infect. In cases of so-called spurius infection, when immature eggs are ingested by a susceptible host, they pass unchanged through the gastrointestinal tract, but are able to immunologically sensitize the host ${ }^{8}$. Their chitinous shell is difficult to digest once inside the host tissues, so it may retard resorption of the lesions and act as adjuvant for host sensitization. Present experiments using eggs alone failed to induce septal fibrosis of the liver. However, the participation of Capillaria eggs in pathogenesis has not been ruled out. Injections of eggs directly into the hepatic parenchyma are far from reproducing the situation in natural infection. Only a few, scattered, isolated eggs were found in the sections examined. In this experimental situation septal fibrosis was not observed. However, it can be assumed that, if the role played by the immature eggs alone in the pathogenesis of septal fibrosis was of some importance, some trace of septal or perisinusoidal fibrosis would at least be expected.

Therefore, the presence of lesions containing both disintegrating worms and eggs appeared essential for the full development of disseminated or systematized septal fibrosis of the liver in rats infected with $C$. hepatica.

\section{REFERENCES}

1. Andrade ZA. Contribution to the study of septal fibrosis of the liver. International Journal of Experimental Pathology 72:553-562, 1991.

2. Barnett JL, Appelman HD, Moseley RH. A familial form of incomplete septal cirrhosis. Gastroenterology 102:674-678, 1992.

3. Bhunchet E, Eishi Y, Wake K. Contribution of immune response to hepatic fibrosis induced by porcine serum. Hepatology 23:811817, 1996.

4. Cheetham RF, Markus MB. Drug treatment of experimental Capillaria hepatica infection in mice. Parasitology Research 77:517-520, 1991.

5. El Gebaldy MW, Nassery SF, Azzouni MZ, Hamouda NA, Allam SR. Effect of mebendazole and ivermectin in experimental hepatic capillariasis: parasitological, scanning electron microscopy and immunological studies. Journal of the Egyptian Society of Parasitology 26:261-274, 1996.
6. Ferreira LA, Andrade ZA. Capillaria hepatica: a cause of septal fibrosis of the liver. Memórias do Instituto Oswaldo Cruz 88:441447, 1993.

7. Gerber MA, Vernace S. Chronic septal hepatitis. Virchow's Archiv (Pathology. Anatomy. Histology) 362:303-309, 1974.

8. Nascimento I, Sadigursky M. Capillaria hepatica: alguns aspectos imunopatológicos da infecção espúria e da infecção verdadeira. Revista da Sociedade Brasileira de Medicina Tropical 19:21-25, 1986.

9. Paronetto F, Popper H. Chronic liver injury induced by immunologic reactions. Cirrhosis following immunization with heterologous sera. The American Journal of Pathology 40: 10871101, 1966.

10. Sciot R, Staessen D, Van Damme B, Van Steenbergen W, Fevery J, Groote J, Desmet VJ. Incomplete septal cirrhosis: histopathological aspects. Histopathology 13:593-603, 1988. 